\title{
Intravesical prostatic protrusion may affect early postoperative continence undergoing robot-assisted radical prostatectomy
}

\author{
Katsuya Hikita", Masashi Honda, Shogo Teraoka, Ryoma Nishikawa, Yuske Kimura, Panagiota Tsounapi,
} Hideto Iwamoto, Shuichi Morizane and Atsushi Takenaka

\begin{abstract}
Background: In this study, we investigated the effect of preoperative prostate morphology, especially intravesical prostatic protrusion (IPP), on continence after robot-assisted radical prostatectomy (RARP).

Methods: Retrospective analysis was applied to patients who underwent RARP between October 2010 and July 2014. The following parameters were assessed in all patients: age, body mass index (BMI), prostate-specific antigen, magnetic resonance imaging and pressure-flow studies findings. The impact of preoperative and intraoperative factors on postoperative urinary incontinence (UI) was assessed using multivariate logistic regression analysis. To evaluate the effects of IPP, the patients were divided into groups according to the IPP length: Group 1, $<5 \mathrm{~mm}$ and Group $2, \geq 5 \mathrm{~mm}$. The International Prostate Symptom Score (IPSS), Overactive Bladder Symptom Score, Quality of Life index and the number of pads used were assessed.
\end{abstract}

Results: A total of 119 patients were eligible for this study. Multivariate analyses showed that IPP (odds ratio (OR) $1.14,95 \%$ confidence interval (CI) 1.02-1.28, $p<0.05$ ) and nerve-sparing (NS) (OR 0.23, 95\% Cl 0.18-0.61, $p<0.01$ ) were significant factors related to $\mathrm{UI}$ in the first month after RARP. Twelve months after RARP, multivariate analyses revealed that only NS is a factor related to postoperative UI (OR $0.23,95 \% \mathrm{Cl} 0.18-0.61, p<0.01)$. The comparison of Groups 1 and 2 indicated significant differences in age $(p<0.01)$, prostate volume $(p<0.01)$, total IPSS and voiding symptom score $(p<0.05)$, compliance $(p<0.01)$, and detrusor pressure at maximum flow $(p<0.01)$. Group 1 had a higher continence rate (38.0\%) than Group $2(20.8 \%)$ in the first month after RARP $(p<0.05)$, but the difference was no longer significant from the third month after RARP. The total IPSS and voiding symptom scores were significantly different between the two groups before RARP, however, the significant difference disappeared from the first month after RARP. Conclusions: The data suggest that IPP affects early postoperative UI. Although NS was strongly involved in UI in the early and later stages after RARP, IPP had no effect on UI in the later stages.

Keywords: Prostate/diagnostic imaging, Prostatectomy/adverse effects, Urinary incontinence/surgery, Robotic surgical procedures/adverse effects, Quality of life

*Correspondence: k-hikita@tottori-u.ac.jp

Division of Urology, Department of Surgery, Faculty of Medicine, Tottori University, 36-1 Nishicho, Yonago, Japan

\section{Background}

To date there is a variety of treatments for localized prostate cancer $(\mathrm{PCa})$ that can be performed, including active surveillance, radiation therapy and radical prostatectomy. In particular, the robot-assisted laparoscopic radical prostatectomy (RARP) has become a widely performed type of treatment in patients with PCa due to low blood 
loss and transfusion rates, shorter hospital stay, and fine surgical manipulation [1]. Although RARP is less invasive than conventional open radical prostatectomy (ORP) or laparoscopic radical prostatectomy (LRP), there is postoperative urinary incontinence (UI), as with other procedures. UI after radical prostatectomy has a negative effect on patient's quality of life (QOL) and has a higher impact in sexual function [2]. So far various surgical techniques have been reported to reduce postoperative UI after RARP [3].

Several studies reported that RARP provides earlier urinary continence compared to ORP and LRP [1]. It has been reported that $17.3 \%$ of patients undergoing RARP had urinary continence immediately after catheter removal. The 12-month urinary recovery after RARP ranged from 84 to $97 \%$ better than after ORP, where urinary recovery ranged from 60 to $93 \%$ and after LRP ranged from 66 to $95 \%[1,4]$.

On the other hand, patient's factors have also been noted regarding UI after surgery. Several studies have suggested that age, body mass index (BMI), preoperative International Prostate Symptom Score (IPSS) and prostate volume (PV) affect early UI after RARP [1]. Patients with severe lower urinary tract symptoms (LUTS) showed improvement in their subjective symptoms after RARP [5]. Alternatively, reports have investigated the association between benign prostatic hyperplasia (BPH) patterns and early continence after RARP [6]. Currently, several markers have been identified as significant in the clinical progression of $\mathrm{BPH}$. Intravesical prostatic protrusion (IPP) predicts the extent of bladder outlet obstruction in pressure-flow studies (PFS). However, there is limited knowledge on the effects of RARP on LUTS, especially in men with both BPH and PCa. RARP is used to treat both $\mathrm{BPH}$ and $\mathrm{PCa}$, and opt for radical surgical removal of the prostate. This study investigates the associations between preoperative $\mathrm{BPH}$ patterns, preoperative LUTS and UI after RARP. In particular, the impact of preoperative IPP on preoperative and postoperative UI were examined in detail.

\section{Methods}

Ethics

This study was conducted at the Division of Urology, Tottori University Hospital, Yonago, Japan. The study was approved by the Tottori University Ethics Committee (No. 2545).

\section{Patients}

Patients who underwent RARP for PCa (stages cT1ccT3b N0 M0) between October 2010 and July 2014 at our department were included in this study. All patients were signed up after being fully briefed in accordance with the institutional ethics committee. Approved informed consent was obtained and patients were informed that the data would be used anonymously for clinical research purposes. All study data were prospectively collected and retrospectively analysed. The age, BMI, prostate-specific antigen (PSA), Gleason score (GS) and clinical stage were recorded. All patients underwent PFS and magnetic resonance imaging (MRI) before RARP. IPSS, Overactive Bladder Symptom Score (OABSS), QOL index and the number of pads used per day were evaluated before RARP and 1-, 3-, 6-, 9- and 12-months after RARP.

\section{Surgical procedures}

All surgical procedures were performed by six surgeons. The four grades of postero-lateral resection of the prostate were the guide for performing the nerve-sparing (NS) techniques. These included: grade 1, intrafascial dissection; grade 2 , interfascial dissection; grade 3 , extrafascial dissection and grade 4, wide dissection [7]. The NS grade which was used, was based on the MRI findings and GS from the biopsy. The surgeon decided the NS grade preoperatively and intraoperatively. In this study, NS was defined as at least unilateral NS grade 1 or 2, while non-NS was defined as a NS grade of 3 or 4 .

\section{Definition of continence and patient questionnaire}

In this study, continence was defined as using no pads, and was assessed in the physician's interview with the patient at each outpatient visit before RARP and 1-, 3-, 6-, 9- and 12-months after RARP. Urinary symptom status was analysed using the IPSS, OABSS and QOL index. The IPSS consists of seven questions to assess voiding symptoms (incomplete emptying, intermittency, weak stream and straining to void) and storage symptoms (frequency, urgency and nocturia) [8].

\section{PFS}

PFS was performed by a single examiner using the standard method prescribed by the International Continence Society, using a Solar Gold urodynamic system (MMS USA Inc., Dover, NH, USA) [9]. An 8-Fr double lumen catheter was inserted into bladder and normal saline was injected at $50 \mathrm{ml} / \mathrm{min}$. A balloon catheter was placed into the rectum and abdominal pressure was measured. Detrusor pressure was defined as the intravesical pressure minus abdominal pressure. The first desire to void (FDV), maximum cystometric capacity (MCC), bladder compliance, detrusor pressure at maximum flow (PdetQmax) and presence of detrusor overactivity (DO) were recorded. 


\section{MRI measurements}

The PV, IPP, membranous urethra length (MUL), membranous urethra width (MUW) and levator thickness (LT) were measured using MRI. The PV was calculated as height $\times$ width $\times$ length $\times \pi / 6$ (axial and mid-sagittal T2-weighted image). The IPP was measured from the tip of the protruding prostate to the base of the bladder (mid-sagittal T2-weighted image). The MUL was measured as the distance from the prostatic apex to the level of the urethra at the penile bulb on coronal T2-weighted image. The MUW was defined as the maximum diameter of the membranous urethra (axial T2-weighted images). LT was calculated as (the outer levator distance minus the inner levator distance)/ 2 on axial T2-weighted image (Fig. 1).

\section{The effect of IPP}

The effect of IPP was investigated by stratifying the IPP into two levels. The patients were subsequently categorised into two groups based on the IPP length: Group $1(<5 \mathrm{~mm})$ and Group $2(\geq 5 \mathrm{~mm})$. To confirm the difference between the two groups, we compared the padfree rate, IPSS, OABSS and QOL index before RARP and at 1-, 3-, 6-, 9- and 12-months after RARP.

\section{Statistical analysis}

The data were presented as median values and interquartile range (IQR) and evaluated using the Mann-Whitney $\mathrm{U}$ test and Yates chi-square test, where a $\mathrm{p}$-value of less than 0.05 was considered significant. Logistic regression analysis was performed to determine independent predictive values of the main risk factors of UI that have been reported in previous studies (age, BMI, PV, IPSS, OABSS, bladder compliance, NS, MUL, LT and IPP) in the first month and 12 months after RARP [10-14]. The predictors were investigated using multivariate analysis to determine which ones were affected by early and longterm UI. The 95\% confidence interval (CI) was calculated for each odds ratio (OR). A p-value of less than 0.05 was considered significant. Statistical analysis was performed using the Statistical Package for the Social Sciences version 19 (IBM, Armonk, NY) software package.

\section{Results}

A total of 119 patients were eligible for this study. The number of patients who did not use pads at 1-, 3-, 6-, 9and 12-months after RARP were 37 (31.0\%), 63 (52.9\%), 82 (68.9\%), 85 (71.4\%) and 91 (76.5\%), respectively.

The median values of patient age, BMI and PSA before RARP were 66 (48-76) years, $23.5(18.0-30.6) \mathrm{kg} / \mathrm{m}^{2}$ and 7.8 (3.2-37.1) $\mathrm{ng} / \mathrm{mL}$, respectively. The MRI evaluation
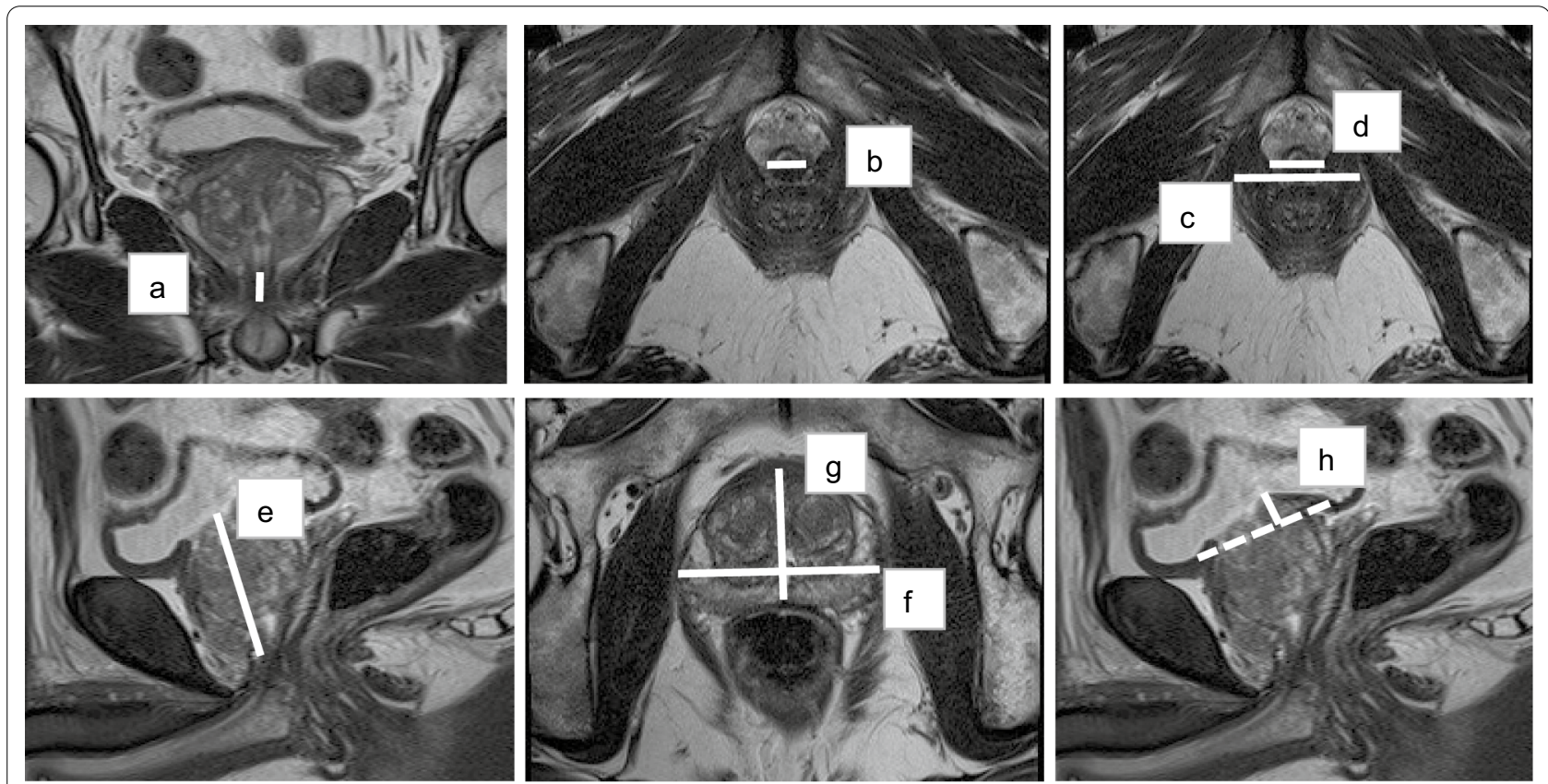

Fig. $1 \mathrm{MRI}$ measurements. $a$ is the MUL. MUL was measured as the distance of the apex of the prostate to the base of the bulbous urethra. $b$ is the MUW. MUW was defined as the maximum diameter of the membranous urethra. LT was calculated as $(c-d) / 2$. $c$ stands for the outer levator distance and $d$ stands for the inner levator distance. PV was calculated as $e \times f \times g \times \pi / 6 / 1000$. $e$ is the maximum height of the prostate, $f$ is the maximal prostate width and $g$ is the maximal prostate length. Intravesical prostatic protrusion $[h(\mathrm{~mm})]$, which is measured from the tip of the protruding prostate to the base of the bladder (mid-sagittal T2-weighted image) 
revealed that the median values of PV, MUL, MUW, LT and IPP before RARP were 26.0 (9.6-66.1) mL, 12.1 (8.916.1) $\mathrm{mm}, 10.6(9.8-13.5) \mathrm{mm}, 11.1(7.9-15.1) \mathrm{mm}$, and $3.8(0.0-16.5) \mathrm{mm}$, respectively. In terms of the clinical stage, 108 patients had $\leq$ T2c, 10 patients had T3a and one patient had T3b disease. Twenty-one patients had a GS of 6, 50 patients had a score of 7 and 48 patients had scores $\geq 8$. According to NCCN risk stratification, 14 patients were considered at low risk, 53 patients were at intermediate risk and 52 patients were at high risk. A NS procedure was performed bilaterally or unilaterally in 51 patients. Lymph node dissection was performed in 105 patients.
The median total IPSS score, IPSS voiding symptom score, storage symptom score, OABSS and QOL index were $6(0-28), 4(0-18), 4(0-12), 3(0-10)$ and $3(0-6)$, respectively. The median compliance, FDV, MCC and PdetQmax were $49.8(5.0-290.2) \mathrm{ml} / \mathrm{cmH}_{2} \mathrm{O}, 144$ (47400) $\mathrm{ml}, 277$ (55-470) $\mathrm{ml}$ and $45(6-90) \mathrm{cmH}_{2} \mathrm{O}$, respectively. DO was identified in 10 patients (Table 1 ).

Multivariate analysis was performed using the risk factors reported in previous studies (age, BMI, PV, IPSS, OABSS, compliance, NS, MUL, LT and IPP) as being linked to UI in the first month and 12 months after RARP, showed that the IPP (OR 1.14, 95\% CI 1.02-1.28, $p<0.05$ ) and NS (OR $0.23,95 \%$ CI $0.18-0.61, p<0.01)$ remained

Table 1 Patients' characteristics

\begin{tabular}{|c|c|c|c|c|}
\hline & Overall population & Group 1 & Group 2 & $p$ value \\
\hline Number of patients & 119 & 71 & 48 & \\
\hline Median age, years (IQR) & $66(48-76)$ & $64(48-76)$ & $69(53-76)$ & $<0.05$ \\
\hline Median BMI, kg/m² (IQR) & $23.5(18.0-30.6)$ & $23.6(18.1-28.9)$ & $22.9(18.0-30.6)$ & 0.8 \\
\hline Median PSA, ng/mL (IQR) & $7.8(3.2-37.1)$ & $7.8(3.2-34.6)$ & $7.7(4.3-37.1)$ & 0.45 \\
\hline \multicolumn{5}{|l|}{ Clinical stage } \\
\hline$<\mathrm{T} 2 \mathrm{C}$ & 108 & 64 & 44 & \multirow[t]{4}{*}{0.96} \\
\hline T3a & 10 & 6 & 4 & \\
\hline $\mathrm{T} 3 \mathrm{~b}$ & 1 & 1 & 0 & \\
\hline T4 & 0 & 0 & 0 & \\
\hline \multicolumn{5}{|l|}{ GS of biopsy } \\
\hline$<6$ & 21 & 13 & 8 & \multirow[t]{3}{*}{0.46} \\
\hline 7 & 50 & 25 & 25 & \\
\hline$>8$ & 48 & 33 & 15 & \\
\hline \multicolumn{5}{|l|}{ Risk class (NCCN) } \\
\hline Low & 14 & 9 & 5 & \multirow[t]{3}{*}{0.54} \\
\hline Intermediate & 53 & 27 & 26 & \\
\hline High & 52 & 35 & 17 & \\
\hline Lymph node dissection (\%) & $105(88.2)$ & $62(87.3)$ & $43(89.6)$ & 0.75 \\
\hline Nerve sparing (\%) & $51(42.8)$ & $28(39.4)$ & $23(47.9)$ & 0.15 \\
\hline Median PV, mL (IQR) & $26.0(9.6-66.1)$ & $24.8(11.1-53.2)$ & $32.8(9.6-66.1)$ & $<0.01$ \\
\hline Median MUL, mm (IQR) & $12.1(8.9-16.1)$ & $12.1(9.1-15.3)$ & $12.9(8.9-16.1)$ & 0.53 \\
\hline Median MUW, mm (IQR) & $10.6(9.8-13.5)$ & $10.8(9.9-13.4)$ & $10.3(9.8-13.5)$ & 0.76 \\
\hline Median LT, mm (IQR) & $11.1(7.9-15.1)$ & $11.0(8.3-15.1)$ & $11.3(7.9-15.1)$ & 0.66 \\
\hline Median IPP, mm (IQR) & $3.8(0.0-16.5)$ & $1.0(0.0-4.9)$ & $7.8(6.2-16.5)$ & $<0.01$ \\
\hline Median IPSS Total score (IQR) & $6(0-28)$ & $6(0-22)$ & $8(0-28)$ & $<0.05$ \\
\hline Median IPSS voiding symptom score (IQR) & $4(0-18)$ & $3(0-15)$ & $5(0-18)$ & $<0.01$ \\
\hline Median IPSS storage symptom score (IQR) & $4(0-12)$ & $3(0-12)$ & $4(0-12)$ & 0.55 \\
\hline Median OABSS score (IQR) & $3(0-10)$ & $2(0-10)$ & $4(2-10)$ & 0.45 \\
\hline Median QOL index (IQR) & $3(0-6)$ & $3(0-6)$ & $3(0-6)$ & 0.35 \\
\hline Median compliance, mL/cmH $\mathrm{C}_{2} \mathrm{O}(\mathrm{IQR})$ & $49.8(5.0-290.2)$ & $55.9(5.0-290.2)$ & $42.4(5.4-153.9)$ & $<0.01$ \\
\hline Median FDV, mL (IQR) & $144(47-400)$ & $144(81-400)$ & $134(47-301)$ & 0.62 \\
\hline Median MCC, mL (IQR) & $277(55-470)$ & $282(120-470)$ & $264(55-431)$ & 0.96 \\
\hline Median PdetQmax, $\mathrm{cmH}_{2} \mathrm{O}(\mathrm{IQR})$ & $45(6-90)$ & $41(6-89)$ & $48(28-90)$ & $<0.01$ \\
\hline $\mathrm{DO}(\%)$ & $10(8.4)$ & $7(9.8)$ & $3(6.2)$ & 0.22 \\
\hline
\end{tabular}


as significant factors in the first month after RARP. At 12 months after RARP, the only factor that remained significantly associated with UI on multivariate analysis was NS (OR 0.88, 95\% CI 0.78-0.99, $p<0.05$ ) (Table 2).

The patients were stratified into two groups according to IPP length: Group $1(<5 \mathrm{~mm}: \mathrm{n}=71)$ and Group $2(\geq 5 \mathrm{~mm}: \mathrm{n}=48)$. The comparison of the two groups indicated significant differences in age $(p<0.01)$, PV $(p<0.01)$, total preoperative IPSS score $(p<0.05)$, preoperative IPSS voiding symptom score $(p<0.01)$, bladder compliance $(p<0.01)$ and PdetQmax $(p<0.01)$ (Table 1$)$.

With respect to the total IPSS and voiding symptom score, a significant difference was observed between the two groups before RARP $(p<0.01)$, but the significant difference disappeared from the first month after RARP. The IPSS storage symptom score, QOL index and OABSS were not significantly different between groups 1 and 2 both before and after RARP (Fig. 2).

The evaluation of UI in Group 1 showed that the number of patients who did not use pads at 1-, 3-, 6-, 9- and 12-months after RARP were 27 (38.0\%), 40 (56.3\%), 50 (70.4\%), 53 (74.6\%) and 55 (77.5\%), respectively. In Group 2 , the number of patients who did not use pads at 1-, 3-, 6-, 9- and 12-months after RARP were 10 (20.8\%), 23 (47.9\%), 32 (66.7\%), 32 (66.7\%) and 36 (75.0\%), respectively. Group 1 had a higher continence rate than Group 2 in the first month after RARP $(\mathrm{p}<0.05)$; however, the significant difference disappeared 3 months onward after RARP (Fig. 2).

\section{Discussion}

The post-RARP UI is influenced by the preoperative patient's characteristics as well as the surgical technique. In a systematic review, the 12-month UI rates ranged from 4 to $31 \%$ with a mean value of $16 \%$ after
RARP [1]. In our study, the number of patients who did not use pads at 1-, 3-, 6-, 9- and 12-months after RARP were 37 (31.0\%), 63 (52.9\%), 82 (68.9\%), 85 (71.4\%) and 91 (76.4\%), respectively. The incontinence rate in this study was higher than in the previous reports. One possible reason for the high UI rate in this study was the older age of patients than in the previous reports $[1,15]$. It might also be related to the surgical technique used. Studies that evaluated the impact of different surgical techniques on UI after RARP found that posterior musculofascial reconstruction with or without anterior reconstruction was associated with a small advantage in the recovery from urinary continence 1 month after RARP $[1,16]$. In our study, both anterior and posterior reconstruction was performed in all cases. Therefore, the effects of the reconstruction could not be assessed. Although bladder neck preservation was not evaluated in this study, it was previously reported to be associated with a higher continence rate after RARP $[12,13]$. With respect to NS, this procedure has been known to favour continence. Retrospective studies showed that better continence rates at 9-12 months after LRP or RARP were achieved in patients with at least one completely spared neurovascular bundle [11]. In our study, NS is a solid factor associated with a higher preserved continence rate from the early to the long-term postoperative period. NS was performed in only 51 cases (42.9\%), which might have contributed to the high rate of UI observed in this study [16].

Besides the surgical technique, several other factors related to UI after RARP have been mentioned. Some reports show that patient age, BMI, MUL, LT, IPP, race, OABSS and severity of preoperative IPSS score are factors associated with the continence rate after RARP [5, 10-12, 19, 20]. Therefore, we performed multivariate analysis based on these factors in this study. NS and IPP

Table 2 Multivariate analyses to identify significant predictors of postoperative urinary incontinence at 1 and 12 months in patients undergoing RARP

\begin{tabular}{|c|c|c|c|c|c|c|}
\hline \multirow[t]{2}{*}{ Predictors } & \multicolumn{3}{|c|}{1 month after RARP } & \multicolumn{3}{|c|}{12 months after RARP } \\
\hline & OR & $95 \% \mathrm{Cl}$ & $p$ & OR & $95 \% \mathrm{Cl}$ & $p$ \\
\hline Age, years & 1.04 & $0.97-1.12$ & 0.23 & 1.03 & $0.95-1.12$ & 0.43 \\
\hline BMI, kg/m² & 0.89 & $0.75-1.01$ & 0.23 & 0.97 & $0.81-1.16$ & 0.72 \\
\hline Nerve sparing, yes/no & 0.23 & $0.18-0.61$ & 0.003 & 0.88 & $0.78-0.99$ & 0.03 \\
\hline $\mathrm{PV}, \mathrm{mL}$ & 1 & $0.96-1.05$ & 0.96 & 1 & $0.96-1.05$ & 0.9 \\
\hline MUL, mm & 0.91 & $0.82-1.00$ & 0.06 & 0.95 & $0.85-1.10$ & 0.39 \\
\hline $\mathrm{LT}, \mathrm{mm}$ & 1.05 & $0.92-1.20$ & 0.45 & 0.98 & $0.87-1.10$ & 0.74 \\
\hline $\mathrm{IPP}, \mathrm{mm}$ & 1.14 & $1.02-1.28$ & 0.02 & 0.99 & $0.87-1.14$ & 0.96 \\
\hline IPSS Total score & 0.95 & $0.82-1.06$ & 0.33 & 1.04 & $0.87-1.14$ & 0.39 \\
\hline OABSS score & 1.07 & $0.79-1.44$ & 0.65 & 1.06 & $0.82-1.37$ & 0.66 \\
\hline Compliance, $\mathrm{mL} / \mathrm{cmH}_{2} \mathrm{O}$ & 0.99 & $0.99-1.01$ & 0.65 & 1.01 & $0.99-1.02$ & 0.2 \\
\hline
\end{tabular}




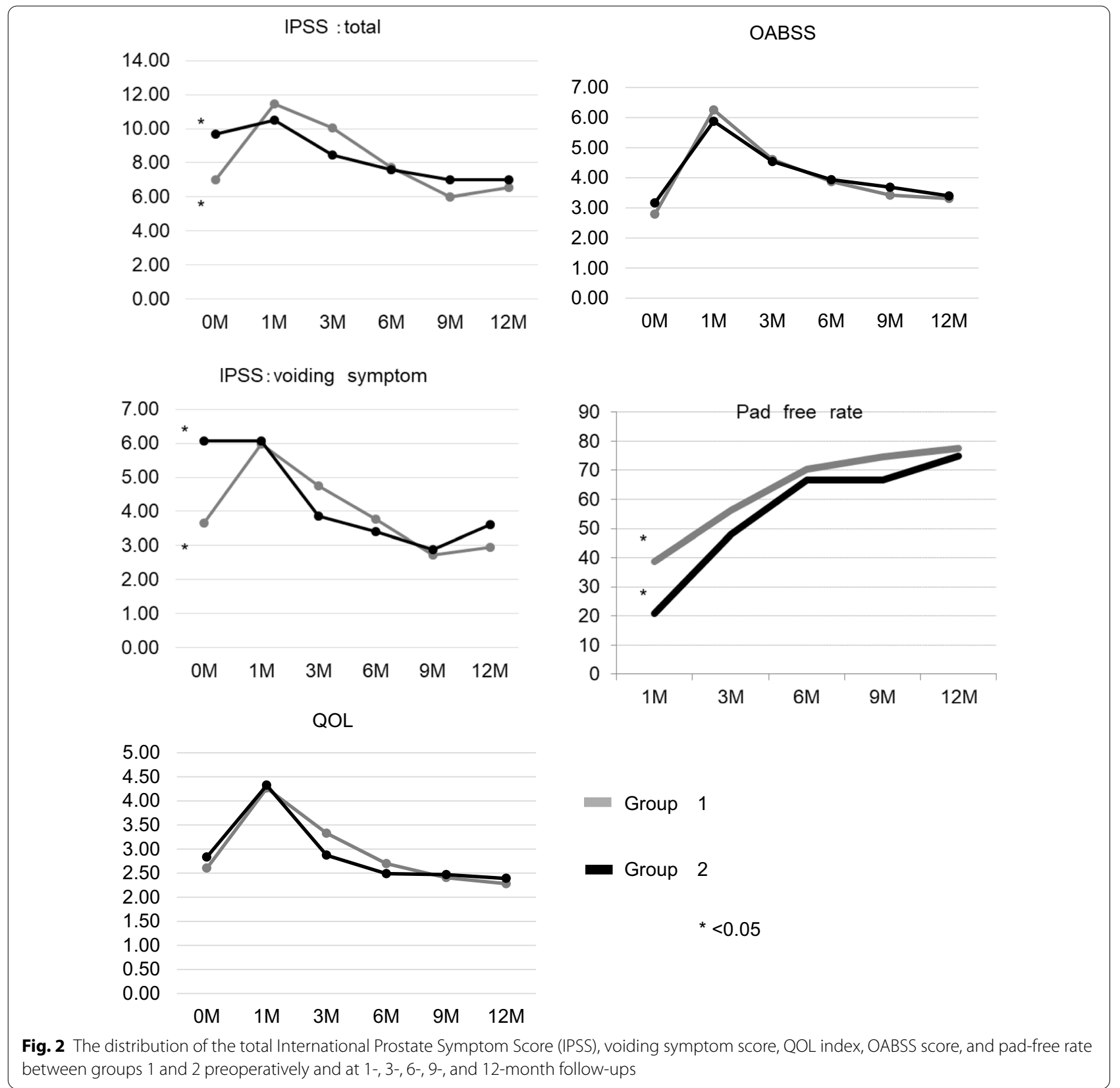

were significant factors for UI during the first month post-RARP. As for NS, as reported by Suardi et al., this factor has an early effect on UI rates and is still a significant factor 12 months postoperatively [16]. However, although IPP affected early postoperative UI, this effect disappeared at 12 months postoperatively.

In this study, we focused on and examined the impact of IPP on UI after RARP. In a previous study, the impact of IPP on the effects of the therapy for BPH was extensively evaluated [21]. RARP provides treatment for both $\mathrm{BPH}$ and $\mathrm{PCa}$; opt for radical surgical removal of the prostate. Therefore, the effect of IPP on preoperative urinary status also affects the urinary status after RARP. Additionally, as Grivas et al. reported that IPP predicts the extent of bladder outlet obstruction seen in PFS, it is understandable that IPP affects both preoperative and post-RARP urinary states [6]. However, Grivas et al. also reported that IPP was not a significant factor affecting the continence rate, although their study evaluated outcomes at only 6 and 12 months after RARP [6]. Alternatively, this study is more detailed with evaluations before RARP and at 1-, 3-, 6-, 9- and 12-months after RARP. In this 
study, IPP was not a significant factor related to the continence rate 12 months after RARP, but was only linked to UI at the first month after surgery. Furthermore, previous reports have also shown that IPP affects UI, with significant differences in the recovery of continence at 3-, 6- and 12-months after surgery [15]. Our study showed that postoperative UI was affected by preoperative IPP at an earlier stage.

Besides the impact of IPP on early post-RARP UI, there were also significant differences between the two groups in bladder compliance, PdetQmax, IPSS total score, IPSS voiding symptom score and PV. A higher grade of IPP would result in a higher degree of subclinical bladder dysfunction before RARP, resulting in a lower rate of urinary continence after RARP. Yamada et al. reviewed 272 patients after RARP. Multivariable analysis showed that the presence of an unstable bladder preoperatively was an independent negative predictor of the recovery of continence within 12 months after surgery [13]. In our study, although IPP affected bladder compliance, there were no significant differences in FDV, MCC, OABSS and IPSS storage symptom score between the two groups. Thus, although IPP potentially have an impact on urinary storage symptoms, no significant difference was found in this study because there were only few cases with a high IPP grade. Hence, different results might have been obtained if the number of cases was higher.

In this study, the total IPSS score and voiding symptom score were preoperatively significantly different between the two groups. However, there was no significant difference after surgery. Therefore, patients with severe preoperative voiding symptoms benefit from RARP.

The limitations of this study were the small number of cases, few cases of severe IPP and lack of evaluation of bladder neck preservation. Since it was difficult to perform bladder neck preservation in high-grade IPP patients, the assessment of bladder neck preservation in cases of IPP facilitates the evaluation of its effect on UI in the future.

Thus, future studies assessing the effect of IPP on UI should include a larger number of severe cases of IPP to enable more detailed study.

\section{Conclusions}

The results of this study suggest that IPP affects urinary continence in the early postoperative period. Although NS was strongly involved in urinary continence in both early and later stages after RARP, IPP had no effect in the later stages. Various preoperative factors are involved in continence after RARP, and IPP is one of those factors. More detailed evaluation of a larger number of cases in the future will help shed more light on this topic.

\section{Abbreviations}

PCa: Prostate cancer; RARP: Robot-assisted radical prostatectomy; ORP: Open radical prostatectomy; UI: Urinary incontinence; QOL: Quality of life; LRP: Laparoscopic radical prostatectomy; BMI: Body mass index; IPSS: International Prostate Symptom Score; PV: Prostate volume; LUTS: Lower urinary tract symptoms; BPH: Benign prostatic hyperplasia; IPP: Intravesical prostatic protrusion; PFS: Pressure-flow study; PSA: Prostate-specific antigen; GS: Gleason score; MRI: Magnetic resonance imaging; OABSS: Overactive Bladder Symptom Score; NS: Nerve-sparing; DO: Detrusor overactivity; FDV: First desire to void; MCC: Maximum cystometric capacity; Pdet Qmax: Detrusor pressure at peak urinary flow rate; MUL: Length of the membranous urethra; MUW: Width of the membranous urethra; LT: Levator thickness; IQR: Interquartile range; Cl: Confidence interval; OR: Odds ratios.

\section{Acknowledgements}

The authors would like to thank Enago (www.enago.jp) for the English language review.

\section{Authors' contributions}

$\mathrm{KH}$ : Project development, data analysis, manuscript writing; $\mathrm{HI}$ and SM: Project development, data collection, data analysis; PT, ST, RN and YK: data analysis; $\mathrm{MH}$ and AT: Project development, Manuscript Revision; YN: Manuscript Revision. All authors read and approved the final manuscript.

\section{Funding}

Not applicable.

\section{Availability of data and materials}

The datasets used and/or analysed during the current study available from the corresponding author on reasonable request.

\section{Ethics approval and consent to participate}

This study was conducted at the Division of Urology, Tottori University Hospital, Yonago, Japan. The study was approved by the Tottori University Ethics Committee (no. 2545). The patients' consent for this study were made by optout, and the data of the patients who declined were not used.

Consent for publication

Not applicable.

\section{Competing interests}

The authors declare that they have no competing interests.

Received: 10 November 2019 Accepted: 13 October 2020 Published online: 21 October 2020

References

1. Ficarra V, Novara G, Rosen RC, Artibani W, Carroll PR, Costello A, et al. Systematic review and meta-analysis of studies reporting urinary continence recovery after robot-assisted radical prostatectomy. EUR Urol. 2012:62:405-17. https://doi.org/10.3349/ymj.2016.57.5.1165.

2. van der Poel HG, Tillier C, de BlokWM, Acar C, van Muilekom EH, van den Bergh RC. Interview-based versus questionnaire-based quality of life outcomes before and after prostatectomy. J Endourol. 2013;11:1411-6. https://doi.org/10.1089/end.2012.0735.

3. Lei Y, Alemozaffar M, Williams SB, Hevelone N, Lipsitz SR, Plaster BA, et al. Altermal division and selective suture ligation of the dorsal vein complex during robot-assisted laparoscopic radical prostatectomy: description of technique and outcomes. EUR Urol. 2011;59:235-43. https://doi. org/10.1016/j.eururo.2010.08.043.

4. Sammon JD, Sharma P, Trinh QD, Ghani KR, Sukumar S, Menon M. Predictors of immediate continence following robot-assisted radical prostatectomy. J Endourol. 2013;27:442-6. https://doi.org/10.1089/end.2012.0312.

5. Gordon A, Skarecky DW, Ahlering T. Long-term outcomes in severe lower urinary tract symptoms in men undergoing robotic-assisted radical prostatectomy. Urology. 2014;84(4):826-31. https://doi.org/10.1016/j.urolo gy.2014.05.052. 
6. Grivas N, van der Roest R, Tillier C, Schouten D, van Muilekom E, Schoots I, van der Poel H, Heijmink S. Patterns of benign prostate hyperplasia based on magnetic resonance imaging are correlated with lower urinary tract symptoms and continence in men undergoing a robot-assisted radical prostatectomy for prostate cancer. Urology. 2017;107:196-201. https:// doi.org/10.1016/j.urology.2017.05.047.

7. Tewari AK, Srivastava A, Huang MW, Robinson BD, Shevchuk MM, Durand M, Sooriakumaran P, Grover S, Yadav R, Mishra N, Mohan S, Brooks DC, Shaikh N, Khanna A, Leung R. Anatomical grades of nerve sparing: a risk-stratified approach to neural-hammock sparing during robot-assisted radical prostatectomy (RARP). BJU Int. 2011;108:984-92. https://doi. org/10.1111/j.1464-410X.2011.10565.X.

8. Steele GS, Sullivan MP, Sleep DJ, Yalla SV. Combination of symptom score, flow rate and prostate volume for predicting bladder outflow obstruction in men with lower urinary tract symptoms. J Urol. 2000;164:344-8. https ://doi.org/10.1016/S0022-5347(05)67356-9.

9. Abrams P, Cardozo L, Fall M, Griffiths D, Rosier P, Ulmsten U, van Kerrebroeck $P$, Victor $A$, Wein $A$. The standardisation of terminology of lower urinary tract function: report from the Standardisation Sub-committee of the International Continence Society. Neurourol Urodyn. 2002;21(2):16778. https://doi.org/10.1002/nau.10052.

10. Lavigueur-Blouin $H$, Noriega AC, Valdivieso R, Hueber PA, Bienz M, Alhathal $\mathrm{N}$, et al. Predictors of early continence following robot-assisted radical prostatectomy. CUAJ. 2015;9:e93-7. https://doi.org/10.5489/ cuaj.2086.

11. Honda M, Kawamoto B, Morizane S, Hikita K, Muraoka K, Sejima T, Takenaka A. A prognostic model for predicting urinary incontinence after robot-assisted radical prostatectomy. Int J Med Robot. 2017;13:e1780. https://doi.org/10.1002/rcs.1780.

12. Jo JK, Hong SK, Byun SS, Zargar H, Autorino R, Lee SE. Urinary continence after robot-assisted laparoscopic radical prostatectomy: the impact of intravesical prostatic protrusion. Yonsei Med J. 2016;57(5):1145-451. https ://doi.org/10.3349/ymj.

13. Yamada Y, Fujimura T, Fukuhara $H$, et al. Overactive bladder is a negative predictor of achieving continence after robot-assisted radical prostatectomy. Int J Urol. 2017;24:749-56. https://doi.org/10.1111/iju.13411.

14. Barnoiu OS, Garcia Galisteo E, Baron Lopez F, Vozmediano Chicharro R, Soler Martinez J, Del Rosal Samaniego JM, Machuca Santacruz J, Baena
GV. Prospective urodynamic model for prediction of urinary incontinence after robot-assisted radical prostatectomy. Urol Int. 2014;92(3):306-9. https://doi.org/10.1159/000354352.

15. Kaye DR, Hyndman ME, Segal RL, Mettee LZ, Trock BJ, Feng Z, et al. Urinary outcomes are significantly affected by nerve sparing quality during radical prostatectomy. Urology. 2013;82(6):1348-53. https://doi. org/10.1016/j.urology.2013.06.067.

16. Suardi N, Moschini M, Gallina A, Gandaglia G, Abdollah F, Capitanio U, Bianchi $M$, et al. Nerve-sparing approach during radical prostatectomy is strongly associated with the rate of postoperative urinary continence recovery. BJU Int. 2013;111:717-22. https://doi.org/10.1111/j.1464410X.2012.11315.x.

17. Friedlander DF, Alemozaffar M, Hevelone ND, et al. Stepwise description and outcomes of bladder neck sparing during robot-assisted laparoscopic radical prostatectomy. J Urol. 2012;188:1754-60. https://doi. org/10.1016/j.juro.2012.07.045.

18. Nyarangi-Dix JN, Radtke JP, Hadaschik B, et al. Impact of complete bladder neck preservation on urinary continence, quality of life and surgical margins after radical prostatectomy: a randomized, controlled, single blind trial. J Urol. 2013;189:891-8. https://doi.org/10.1016/j. juro.2012.09.082.

19. Smolski M, Esler RC, Turo R, Collins GN, Oakley N, Brough R. Bladder neck sparing in radical prostatectomy. Indian J Urol. 2013;29(4):338-44. https:// doi.org/10.4103/0970-1591.

20. Song W, Kim CK, Park BK, et al. Impact of preoperative and postoperative membranous urethral length measured by 3 Tesla magnetic resonance imaging on urinary continence recovery after robotic-assisted radical prostatectomy. Can Urol Assoc J. 2017;11:E93-99. https://doi.org/10.5489/ cuaj.4035.

21. Lim KB, Ho H, Foo KT, Wong MY, Fook-Chong S. Comparison of intravesical prostatic protrusion, prostate volume and serum prostatic-specific antigen in the evaluation of bladder outlet obstruction. Int J Urol. 2006;13:1509-13. https://doi.org/10.1111/j.1442-2042.2006.01611.x.

\section{Publisher's Note}

Springer Nature remains neutral with regard to jurisdictional claims in published maps and institutional affiliations.
Ready to submit your research? Choose BMC and benefit from:

- fast, convenient online submission

- thorough peer review by experienced researchers in your field

- rapid publication on acceptance

- support for research data, including large and complex data types

- gold Open Access which fosters wider collaboration and increased citations

- maximum visibility for your research: over 100M website views per year

At BMC, research is always in progress.

Learn more biomedcentral.com/submissions 